\title{
Is There a Long-Term Criminogenic Effect of the Exposure to a Paternal Conviction During Upbringing? An Analysis of Full Siblings Using Swedish Register Data
}

\author{
Fredrik Sivertsson $^{1}$ (iD) Christoffer Carlsson $^{1}$ (D) Andreas Hoherz $^{2}$
}

Accepted: 20 August 2021 / Published online: 26 August 2021

(c) The Author(s) 2021

\begin{abstract}
Objectives The current study analyzed the association between a final paternal conviction that occurred sometime 10 years prior to birth through age 14 and subsequent child conviction risk to age 25 .

Methods We used Swedish register-based data on a two-generation dataset originating from a parental generation born in 1953. We employed a combination of population-averaged models that controlled for measured confounding together with an analysis of full siblings that ruled out unmeasured confounding shared between full siblings.

Results The results showed that boys, but not girls, who were exposed to a paternal conviction during upbringing had an increased risk of being convicted themselves, net of measured and unmeasured familial confounds. There was, however, little indication for an ageeffect at the time of a final paternal conviction, and there were no significant differences in violent crime between exposure-discordant siblings.

Conclusions The results provide evidence for an effect of the exposure to a paternal conviction on child subsequent conviction risk that cannot merely be explained by familial factors shared between full siblings. These results are, however, conditional on gender and on the type of criminal outcome.
\end{abstract}

Keywords Intergenerational transmission of crime $\cdot$ Sibling-comparisons $\cdot$ Linear probability models $\cdot$ Conviction data

Fredrik Sivertsson

fredrik.sivertsson@ criminology.su.se

Christoffer Carlsson

christoffer.carlsson@criminology.su.se

Andreas Hoherz

andreas.hoherz@sociology.su.se

1 Department of Criminology, Stockholm University, Stockholm, Sweden

2 Department of Sociology, Stockholm University, Stockholm, Sweden 


\section{Introduction}

Children whose parents exhibit criminal behavior have an increased risk of displaying criminal behavior themselves. A recent meta-analysis of 23 samples from 25 studies found that children whose parents had a criminal history were 2.4 times more likely to be involved in crime than other children (Besemer et al. 2017; see also van de Weijer et al. 2017). In this context, the link between father and son has been especially welldocumented, but the mere association is present in all parent-child gender combinations (Besemer et al. 2017). The intergenerational continuity of crime has generated a number of theories and stimulated empirical scrutiny. From a larger life-course perspective, this branch of research connects well with the principle of linked lives and the question as to why inequality around a multitude of dimensions tends to be reproduced across successive generations (Elder et al. 2003).

In attempting to understand the mechanisms accounting for the intergenerational continuity of crime, prior studies have, to some extent, considered when the parent was criminally active, that is, if this occurred before the birth of the child and/or during different developmental stages of the upbringing years (Besemer et al. 2017). From what is known of crime and the life course, the normative sequence is one where the peak years of delinquency have played out before the adult markers of steady employment, marriage, and family formation (Massoglia and Uggen 2010). However, for some, the transition to parenthood does not align with the cessation of offending, and children of these parents may be considered a particularly vulnerable group with regard to upbringing conditions and subsequent involvement in crime (Besemer 2014; Bijleveld and Wijkman 2009; Hjalmarsson and Lindqvist 2012; Rowe and Farrington 1997).

Indeed, a number of criminological theories hold that childhood or adolescent experiences exert a direct, and long-term, effect on later life adaption because the experience occurs during a sensitive developmental period of life. The foundations for the development of criminal offending may already be operating in early childhood, tied to the disadvantages of an overall criminogenic environment. For example, Gottfredson and Hirschi (1990) posit that the root causes for criminal offending has to do with structural factors linked to childrearing capabilities, especially the development of self-control, which in turn affects criminal behavior across the succeeding life course (see also Wikström et al. 2012). Social learning and role modeling theory, on the other hand, put strong emphasis on the teenage years as the awareness of parental crime, and parental contact with the criminal justice system, may be connected to learning mechanisms and the establishment of a criminal identity (Besemer 2014).

Aside from the exposure to a criminal parent, a parental conviction may also capture the deleterious effects of criminal justice processing. The process of collateral consequences of imprisonment has been theorized in a number of ways, the most prominent one being based on Coleman's notion of human and social capital (1990). Following Hagan and Dinovitzer (1999), such loss of capital can be understood as constituting several, often intertwined mechanisms, e.g. an (increased) economic deprivation of the family, a loss of parental socialization through role modelling, support, and supervision, and a form of stigmatization through labelling. This goes for shorter prison stays too, which are common in the Nordic penal welfare states and have been shown to be deleterious with regard to a number of long-term outcomes in children, including crime (Dobbie et al. 2018; Wildeman and Andersen 2017). As a form of collateral consequence, criminal justice processing of a parent following his/her criminal behavior may thus in 
itself cause dysfunctions in the family and have a long-term criminogenic effect on the child (Van de Rakt et al. 2012).

Although there are sound theoretical reasons to believe that the exposure to parental criminal behavior and criminal justice contact is somehow causally related to child subsequent offending, the systematic review carried out by Besemer et al. (2017, p. 171) located a set of methodological limitations in this regard:

Although we retrieved a reasonably large number of samples, none of these studies had experimental or even quasi-experimental designs. No studies examined change in offspring behavior from before to after parental CB [criminal behavior], and in only four studies did parental offending clearly precede offspring offending.

The fact that observational studies have found that children of convicted parents are worse off than other children, does not necessarily mean that the mere exposure to parental criminal offending and/or criminal justice processing exerts a direct effect on the child's criminal behavior. Parents who were convicted during the upbringing years of their children may, in a broad sense, have a higher accumulation of risk factors than parents who were not, and these may be systematically linked to their children's criminal offending. In observational studies, parental criminal history has been highlighted as an important proxy for criminal propensity and risk factors that are transmitted across generations and may confound any degree of timing effects (e.g. Van de Rakt et al. 2010). Additionally, comparing children exposed to a parental conviction during upbringing to children where the parent's final conviction occurred prior to their birth, indicates that much of the difference in conviction risk is linked to familial factors such as low socioeconomic status, poor housing, large family size, and teenage motherhood (Besemer 2014). Still, as indicated by Besemer et al. (2017), the observational nature of most previous studies have hampered the identification of unmeasured confounding. This, in turn, calls into question the extent to which the exposure to parental criminal behavior and criminal justice processing exert an effect on subsequent child crime.

In general, rigorous tests of causal inference require study designs which account for unmeasured confounding. Family-based designs, in particular, utilize the fact that relatives share a number of factors which may be hard to measure and would cause confounding on familial factors in a traditional regression-based framework (D'Onofrio et al. 2013). For example, in a sufficiently large sample, comparing full biological siblings controls for all unmeasured confounding shared between those siblings, such as genetic makeup, parental resources and parenting styles (D'Onofrio et al. 2010). ${ }^{1}$ As noted by Kuja-Halkola et al. (2012), with respect to potential familial confounders, these may not be measurable (e.g. genetic predispositions), impractical to measure in large-scale studies (such as emotional

\footnotetext{
1 Comparing exposure-discordant full siblings adjusts for family-constant confounding (i.e. that are constant in full siblings), including both genetic and shared environmental factors. Consequently, the familyconstant confounders are not confounders in the sibling analysis, since a variable can only be a confounder if it is associated with the exposure. Full siblings share 50\% of their genes and are not identical in their genetic makeup. However, through a process called meiosis, alleles are randomly distributed from parents to offspring (Lahey and D'Onofrio 2010). Genetic factors passively passed down from either parent (so called passive Gene-Environment correlations) that confound the association between exposure and outcome are, as noted, accounted for in sufficiently large samples (Lahey and D'Onofrio 2010, p. 320). For example, if a father was convicted during the upbringing of one of his children but not the other, the two siblings would be equally likely to passively receive paternal alleles associated with the paternal risk of conviction and offspring criminal offending.
} 
neglect during upbringing), and it could also be that important confounders have not been identified yet (p. 740). Importantly, such familial factors contribute to the non-random selection of children into social environments where they are more or less likely to be exposed to adversity, including the exposure to parental criminal behavior and criminal justice processing. Studies in this tradition have demonstrated the importance of unmeasured familial confounds for a number of well-established predictors of crime, including family income (Sariaslan et al. 2014), neighborhood deprivation (Sariaslan et al. 2013), and teenage motherhood (Coyne et al. 2013).

Although rare, there are a number of recent studies that have employed family-based designs to evaluate whether or not the exposure to parental crime is causally linked to the child's future criminal behavior. In one of these, Connolly and Kavish (2019) analyzed the association between adverse childhood experiences, including the exposure to a convicted parent, and subsequent trajectories of delinquency. They used a combination of traditional population-averaged models controlling for measured confounding, and a model that restricted the variation of exposure to childhood adversity between full siblings. The results showed that the association was attenuated when controlling for measured and unmeasured sibling-shared confounds, but that childhood adversity remained a significant predictor of starting levels of delinquent behavior. There was, however, no significant difference in rates of decline, thus suggesting that developmental trajectories of delinquency were not affected by the exposure to childhood adversity (see also Connolly 2020).

In a register-based study, Aaltonen and Mikkonen (2018) analyzed the frequency and timing of parental criminal offending between ages 7 and 15 and subsequent child crime between ages 15 and 17. Separating the variance of children's crime into between- and within-family components, they found a positive association between age at exposure and offspring criminal offending in unrelated children, and when controlling for measured background factors. They did not, however, find a significant association between age-discordant siblings. The same result was found when they changed the exposure to the frequency of parental offenses during upbringing. Aaltonen and Mikkonen concluded that the age-effect they found in the between-family analyses might reflect familial confounding, but also noted that their data was somewhat limited with regard to both the age of exposure and outcome.

To summarize, there is a need for further empirical scrutiny with respect to the mechanisms involved in producing the intergenerational continuity in crime. Although a number of criminological theories in this context posit a causal meaning to the exposure to parental criminal offending and criminal justice processing, there are also reasons to believe that much of this association is explained by familial background factors. The few quasi-experimental studies that have assessed this association are inconclusive, and there is a further need to assess plausible alternative explanations using study designs and methods capable of controlling for unmeasured familial confounds.

\section{The Current Study}

Children with a convicted parent is a heterogeneous group-some children have parents with a distant criminal past whereas others are exposed to parental criminal offending and criminal justice processing during different developmental stages of childhood and adolescence. Building on this premise, the overarching aim of the current study is to assess (1) if children who experience a final paternal conviction during their upbringing years (i.e. exposed) are at an increased risk for being convicted themselves, compared 
to children whose father was convicted prior to their birth but not after (i.e. unexposed), and (2) if children who experience a final paternal conviction during different ages of their upbringing years (i.e. timing) differ in their subsequent conviction risk.

We use Swedish population-based register data and analyze the link between paternal convictions and the children's conviction risk in a dataset comprising two generations, with a parental generation of all individuals born in 1953 and their siblings. We focus on a population of children, and a subpopulation of full siblings, for whom the father was convicted for the last time in one of the years spanning ten years prior to birth through age 14, and who we could follow with conviction data until age 25 . We analyze the association between the child's age at a final paternal conviction and his or her subsequent criminal offending (as measured by conviction data) from age 15 to age 25 by means of linear probability models. We estimate a set of population-averaged models, which account for measured confounding, and sibling-fixed effects models, which account for all unmeasured confounding shared between full siblings. In addition, we carry out non-parametric comparisons of exposure-discordant (i.e. before and after birth) children and full siblings by means of Kaplan-Meier cumulative probability functions. As a final step in the analysis, we model the association between a final paternal conviction and the children's conviction risk for males/brothers and females/sisters separately, to explore if the effects in the main models are driven by males or females.

There are three particular strengths with this study. First, the population of children is drawn from a relatively old population of parents with a median birth year of 1953 and we follow both parents and their children with detailed conviction data from 1973 to 2017. Because the majority of fathers are followed until retirement age, it is possible to reliably distinguish between children whose fathers ended their criminal careers at different points in time before and during their children's lives; a fundamental prerequisite to not confuse groups of differently exposed children. The length of the data also lets us measure the outcome of convicted crime in children over a ten-year period between ages 15 (i.e. the age of criminal responsibility in Sweden) and 25, thus covering the peak years of criminal offending according to the well-established relationship between age and crime (DeLisi and Piquero 2011). Second, we use a combination of populationaveraged models controlling for measured confounding and sibling fixed-effects models that control for all unmeasured confounding that is shared by full siblings. Third, our analyses are based on high quality register data, allowing us to analyze the intergenerational continuity of crime with good temporal precision, in a dataset which does not suffer from small sample sizes, reporting bias, or attrition.

The main strength with the sibling models is that they rule out all familial confounds that are shared between full siblings. The exposure-discordant sibling analysis in the current study entails a breakdown of families where a shared biological father was convicted for his last time after the transition to parenthood but before the birth of the next child in line, where the siblings shared the same biological mother (i.e. full siblings). While the population-averaged models are not able to rule out sibling-shared unmeasured confounding, they concern a much larger sample of children and are good at dealing with measured confounding we cannot control for in the sibling-models, such as birth year and birth order (we discuss these issues of the sibling design below). Hence, these methods have their strengths and weaknesses, and together they strengthen the inference for an eventual direct effect of the exposure to a paternal conviction on the risk for a child's subsequent conviction (see also Aaltonen and Mikkonen 2018; Connolly 2020). 


\section{Data and Methods}

The population is a subset of individuals included in RELINK53, a new register-based dataset collected in 2017/18, consisting of all individuals born in 1953 who lived in Sweden in 1960, 1965 and/or 1968, as well as their ascendant, contemporaneous and descendant family members. ${ }^{2}$ From this dataset we defined the parental generation as all individuals born in 1953 and their siblings. Biological family linkages (both biological parents) were identified through the Swedish multigenerational register and convictions data, and mortality and migration data were merged to all family members. We included all children to the parental generation (1) whose father had been convicted for a final time ten years prior to birth through age $14 ;(2)$ who were at risk of being convicted for a crime at age 15 (i.e. who were alive and had not migrated at age 15); (3) could be followed at least until age 25; and (4) for whom both parents could be identified through the multigenerational register - a total of 96774 children nested in 58980 families. This includes 39679 same-sex full siblings who were discordant in the yearly timing of a final paternal conviction within the age window and thereby comprise the sample for the sibling analyses. The fathers had reached a median age of 64 at follow-up, and 99 percent had reached at least age 50, and none of the children had a father who had been convicted in the outcome period at age 15 to 25 . We may therefore with good reliability measure the final paternal conviction in the children's lives, and also have good control over the time ordering between exposure and outcome, thereby avoiding the risk for reverse causation (see Besemer et al. 2017).

\section{Swedish Conviction Data}

The current study may be viewed as part of a tradition of Nordic criminological research that utilizes administrative data to measure criminal behavior and criminal sanctions at the individual level (see Lyngstad and Skardhamar 2011). In this context, conviction records may generally be said to capture offenders who have committed several offenses, and/or serious offenses, and/or traditional person- and property-oriented offenses (Kyvsgaard 2002). Although a main limitation with official crime data is that a large share of criminal offenses are undetected, Swedish conviction data has been characterized as an official data source that has a relatively high degree of coverage with respect to criminal offenses (von Hofer 2014). This is in part because Swedish police and prosecutors are required to report all offenses that come to their attention, and that there are no legal grounds for the use of discretion in the handling of the criminal offenses during this phase of the criminal justice process (von Hofer 2014). ${ }^{3}$ Furthermore, if a prison sentence is not the typical outcome on the basis of the penal code, the prosecutor can choose to issue a summary sanction order or a waiver of prosecution. These types of sanctions are also included in the conviction

\footnotetext{
2 The data was collected in a recently launched research program called Reproduction of inequality through linked lives (RELINK). This project is essentially a follow-up of a Swedish longitudinal study formerly known as the Metropolitan study and later the Stockholm Birth Cohort Study. This follow-up was made through probability matching on the population registers used in the current study (for an overview of the data collection and cohort profile, see Almquist et al. 2019).

3 The Swedish police only have a sanctioning mandate in the imposition of fines for certain minor traffic offenses such as speeding, and these offenses are therefore not included in convictions data.
} 
register. ${ }^{4}$ Waivers of prosecution and summary sanction orders together constitute around half of all convictions in the convictions register from 1973 to present day.

\section{Methodological Considerations}

It is important to note that longitudinal criminological studies that use official data do not only measure the etiology of criminal behavior, but also the behavior of the criminal justice system (Bushway and Tahamont 2016). In Sweden, a conviction is a quite heterogeneous measure of exposure as it may indicate a wide variety of rule-breaking behavior, which may also yield in a number of different custodial or non-custodial sanctions. As reviewed above, theories about the intergenerational continuity in crime range from mechanisms related to the exposure to parental criminal offending and to criminal justice processing respectively. Given our use of conviction data, we cannot separate between these mechanisms but have to assume that a parental conviction likely captures both.

Aside from the overall conviction risk in children, we analyze the subcategories of violent and property crime, since these may be more or less tied to familial mechanisms and/ or other social causes. Whereas violent crime has been shown to be more strongly tied to familial confounds (Frisell et al. 2011; Kendler et al. 2015), property crime make up a large part of adolescence-limited crime and may, generally, be more tied to social processes outside of the family, such as those related to peers and routine activities. Because the age of criminal responsibility in Sweden is 15 , we lack coverage of criminal behavior prior to this age. Still, our follow-up, covering a ten year period during which crime typically peaks and starts to decline, ought to be a rather reliable method to measure the prevalence of persons who commit crime more frequently. As argued by von Hofer (2014), these individuals are likely to be "arrested and convicted-sooner or later-irrespective of short-term trends in the clearance rate and the likelihood of arrests leading to convictions" (p. 171).

A limitation with the sibling design is that these models restrict the study population to families who have at least two full siblings with different birth years and birth orders. Aside from the threat to external validity (e.g. single-child families are excluded), we are limited in our capacity to control for these variables as they are collinear with the exposure to a final paternal conviction (i.e. it is always the older sibling who is exposed). Given the decline in convictions across successive cohorts during recent decades in Sweden (von Hofer 2014), the estimates in the sibling model are likely overestimated, to some degree. However, we also present the results for children who were born within different lengths of time after the final paternal conviction occurred. Comparing these groups of unexposed children are informative with regard to the extent by which our results may be driven by period effects.

When it comes to birth order, there are reasons to believe that our estimates are underestimated due to our inability to control for this variable. Previous studies indicate that laterborn siblings are generally more disadvantaged than are first-borns (e.g. Modin 2002), and

\footnotetext{
${ }^{4}$ For the prosecutor to issue a waiver of prosecution or a summary sanction order, there cannot be any uncertainty with regard to the guilt of the suspect, which in practice means that the suspect has to admit having committed the crime. Both of these sanction relate to less serious crimes and typically result in a fine, but a waiver of prosecution is often given to individuals who are below the age of 18 and who have no history of recorded crime. It may also be noted that, in contrast to comparable countries such as the US, there is no youth court system in Sweden, and sanctioning decisions relating to both juveniles and adults are made by the same courts.
} 
a recent study provides solid evidence for this also being the case with delinquency, in both a Nordic and Anglo-Saxon context (Breining et al. 2020). Moreover, any degree of sibling carryover effects, where the exposure and outcome of one sibling affect the exposure and outcome of another sibling (Sjölander et al. 2016), would primarily result from the older sibling influencing the behavior of the younger (Farrington 2002; Kendler et al. 2015; Mikkonen et al. 2020). Given such a direction of sibling influence, the effects in our exposurediscordant design would most likely be downwardly biased as it is always the older sibling who is exposed to a paternal conviction.

\section{Variables}

From the conviction register we extracted information on crime type, type of sanction, the date of conviction, and the date of the crime. Our main outcome variables are any crime, violent crime, and property crime. Any crime is defined as all acts described in Swedish penal law or special laws that result in a criminal sanction. Violent crime includes homicide, manslaughter, assault, robbery, kidnapping, threat, unlawful coercion, unlawful threat, rape, molestation, assault or threat to a public servant, and violent resistance. Property crime includes theft, grand theft auto, and shoplifting.

The main explanatory variable is the age at the final paternal conviction, constructed by subtracting the date of the last recorded conviction from the birth date of the child. While the date of the conviction was available in exact days, the birth date was available in a monthly format, thus yielding the precision in months. We constructed a dummy variable that took the value of 1 for individuals exposed to a final paternal conviction after birth, and also five-year age dummies to contrast different age periods over the full time window from ten years prior to birth until age 14 .

The following control variables were constructed to be included in the population-averaged models: a dummy variable taking one for a final paternal prison sanction; a dummy variable taking one for a final paternal violent conviction; dummy variables for prior paternal conviction frequency categorized into no prior convictions (reference category), 1, 2, 3, 4 , and $>=5$; dummy variables for accumulated prior paternal prison time categorized into no prison time (reference category), $<3$ months, 3-12 months, and $>12$ months; a dummy for whether or not the father had a criminal history of violence; a dummy for whether or not the mother was convicted at any time prior to age 15; a dummy for female; dummy variables for birth year; a dummy for single child families; dummy variables for birth order in full families and categorized as 1st born (reference category), 2nd born, 3rd born, and 4th born or higher; and a continuous variable measuring the maternal age at birth.

\section{Analytical Strategy}

We employed linear probability models (LPMs) to study the effects of age of paternal conviction on the child's conviction probability. LPMs are consistent estimators for binary outcomes (Angrist and Pischke 2009), and allow for direct comparisons of coefficients across different models (Mood 2010). ${ }^{5}$ We estimated clustered standard errors to account for the

\footnotetext{
5 Since we have an event-dataset with good precision in the timing of both paternal and child convictions, we estimated the same set of models using Cox proportional hazard regression. An advantage of Cox models is that they handle right-censored data due to death and migration (Allison 2014). In LPM, all individuals who died or migrated before age 25 were excluded. However, these events were rare in our sample (see Table 1). A downside of Cox models in a within-family setting is that they only estimate effects for families
} 
fact that observations are not independent but comprise children nested in families (Stock and Watson 2008). ${ }^{6}$

We estimated a set of population-averaged models (in the full sample) and sibling fixed-effects models (in the sibling sample), where the main independent variable was either a dummy variable for exposure after birth (reference category before birth) or a set of dummy variables for age at exposure in 5 -year intervals (i.e. -10 to $-6 ;-5$ to -1 ; $0-4 ; 5-9 ; 10-14)$. Model 1 only included the main independent variable to examine the bivariate association. Model 2 included measured controls for confounding (see Variables above). Finally, in Model 3, we employed sibling fixed-effects. All families with at least two siblings who were discordant in the exposure (before and after birth or age of exposure, depending on model) were included in these analyses.

Since our follow-up of the children's conviction risk extends over emerging adulthood to age 25, we also estimated non-parametric Kaplan-Meier cumulative probability functions to explore whether or not there were any degree of difference during the ages when the children were convicted (see also D'Onofrio et al. 2010). Kaplan-Meier cumulative probability functions are equivalent to Kaplan-Meier survival curves but measure the failure rate instead of the rate of survival. These functions thus complement the point estimates from the LPMs since they allow us to see if there is any particular stage between ages 15 and 25 when children begin to differ in their conviction risk. We estimated these functions both to show the bivariate association between age at exposure to a parental conviction and the children's conviction risk in the full sample, and in the sample of full siblings who were exposure-discordant (i.e. before and after birth) at their final paternal conviction. These curves were right-censored at the time of decease or emigration.

Gender has been highlighted as an important variable to control for in sibling designs (D'Onofrio et al. 2013). This is particularly relevant when examining an outcome that typically differs substantially between males and females, such as criminal convictions. To make sure that there would not be any systematic gender differences in exposure-discordant siblings, we made sure that brothers were only compared to their brothers and sisters to their sisters. As a final step, given our focus on the final paternal conviction, we also modeled the association between a final paternal conviction and child conviction risk separately for males/brothers and females/sisters. This analysis basically shows if the effects in the main models are driven by males or females.

\section{Sensitivity Analyses ${ }^{7}$}

Except for the point in time before and after the birth of the child, the five-year age-intervals are arbitrarily chosen. We therefore analyzed the association between the child's age at paternal conviction and the child's conviction risk with age in annual and biannual categories, in order to explore if we could justify another categorization of age. Overall, we found a similar age trend, and could not find any particular cut-off where the estimates changed substantially.

\footnotetext{
Footnote 5 (continued)

where at least one sibling was convicted, which decreases our statistical power substantially, particularly in relation to violent crime (see Allison 2009). Importantly, the estimates from the LPM and Cox models were substantially the same although the standard errors were larger in the latter.

6 We used Stata version 15. For the traditional regression analyses we used the reg command and for the fixed-effects models we used the regfhd package (Correia 2017).

7 All sensitivity analyses are available upon request.
} 
We also carried out a set of sensitivity analyses to see if the results were influenced by the left-censored data. First, children born before 1983 are not fully covered on paternal convictions ten years prior to their birth (e.g. the cohort born in 1982 is followed nine years prior to birth, the cohort born in 1981 is followed eight years prior to birth, and so on). We therefore estimated the models for children born 1983 and later. Second, we do not cover the full paternal criminal history among children whose fathers were born before 1958 (in other words, individuals born in 1958 or later were fully covered on criminal history as they turned age 15 in 1973). Since prior paternal conviction frequency is arguably one of the most important confounders when analyzing a timing effect of paternal convictions (e.g. Besemer 2014), we estimated the models on children born to fathers with full criminal history (fathers born in 1958 and later). Third, the transition to parenthood occurred at a wide range of different ages for the fathers in our sample. To make sure that the results were not driven by particularly young fathers, we estimated the models for all families where the father was at least 25 years old at the time of the first-born child. Importantly, in the sibling analyses, we control for all factors that are shared between full siblings by design, among them the full parental history including prior criminal offending and convictions.

Finally, to check the robustness of our results across types of paternal convictions, we carried out subsets of analyses in exposure-discordant children and full siblings by type of final paternal conviction. We separated between those paternal convictions that did, or did not, include a violent crime, as well as between those that did, or did not, result in a prison sanction. These analyses thus yielded a break-down of children and full siblings whose fathers' last conviction were of a particular type (non-violent, violent, conditional, or prison). The results showed that the bivariate association was somewhat stronger when the final paternal conviction included a violent crime or yielded a custodial sanction, but the substantial results were replicated in the population-averaged multivariate models and sibling FE models.

\section{Results}

Table 1 describes the full sample of children (a) and the subsample of full siblings (b) with regard to the outcome and background characteristics. Overall, the sibling sample is similar to the full sample in most characteristics. In the full sample, 20.6 percent were convicted between ages 15 and 25 ( $6 \%$ for a violent crime and $9.6 \%$ for a property crime) whereas $19.8 \%$ in the sibling sample were convicted at the same ages $(5.8 \%$ for a violent crime and $9.1 \%$ for a property crime). The final paternal conviction was related to a violent crime in $19.3 \%$ (17.4\% in the sibling sample), and in only $9 \%(8.2 \%$ in the sibling sample) did the final paternal conviction yield a prison sanction. Turning to paternal criminal history (i.e. before the final paternal conviction), the majority of children had fathers with no prior convictions (58.6\% and 62.2\% respectively), and no history of imprisonment (90.3\% and $92 \%$ ). A small proportion of children (6.8\% and $5.3 \%$ respectively) had frequently convicted fathers ( 5 or more convictions) and/or fathers who had been convicted for violent crime $(10.4 \%$ and $8.9 \%)$, and/or sentenced to prison for an accumulated time of more than 1 year (1.7\% and $1.2 \%)$. In the full sample, $14 \%$ had a mother with at least one conviction whereas $12.4 \%$ in the sibling sample had a convicted mother. With regard to demographic characteristics and censoring variables there were no substantial differences, with the exception 
Table 1 Descriptive statistics on child outcome and background characteristics in full sample of children (a) and in sibling sample (b)

\begin{tabular}{|c|c|c|c|c|}
\hline & \multicolumn{2}{|c|}{ (a) Full sample } & \multicolumn{2}{|c|}{ (b) Sibling sample } \\
\hline & Mean & SD & Mean & SD \\
\hline \multicolumn{5}{|c|}{ Child outcomes at ages $15-25$} \\
\hline Any conviction & 0.206 & 0.405 & 0.198 & 0.398 \\
\hline Violent conviction & 0.060 & 0.238 & 0.058 & 0.233 \\
\hline Property conviction & 0.096 & 0.294 & 0.091 & 0.288 \\
\hline \multicolumn{5}{|c|}{ Type of final paternal conviction } \\
\hline Violent conviction & 0.193 & 0.395 & 0.174 & 0.379 \\
\hline Prison sanction & 0.090 & 0.287 & 0.082 & 0.274 \\
\hline \multicolumn{5}{|l|}{ Paternal criminal history } \\
\hline \multicolumn{5}{|l|}{ Conviction frequency } \\
\hline No prior convictions & 0.586 & 0.492 & 0.622 & 0.485 \\
\hline 1 prior conviction & 0.191 & 0.393 & 0.189 & 0.391 \\
\hline 2 prior convictions & 0.083 & 0.276 & 0.078 & 0.269 \\
\hline 3 prior convictions & 0.045 & 0.206 & 0.036 & 0.187 \\
\hline 4 prior convictions & 0.026 & 0.159 & 0.021 & 0.145 \\
\hline$>=5$ prior convictions & 0.068 & 0.252 & 0.053 & 0.225 \\
\hline \multicolumn{5}{|c|}{ Accumulated imposed prison time } \\
\hline No prior prison time & 0.903 & 0.295 & 0.920 & 0.271 \\
\hline$<3$ months & 0.054 & 0.225 & 0.048 & 0.213 \\
\hline $3-12$ months & 0.026 & 0.160 & 0.020 & 0.141 \\
\hline$>12$ months & 0.017 & 0.128 & 0.012 & 0.109 \\
\hline Violent conviction & 0.104 & 0.305 & 0.089 & 0.285 \\
\hline Maternal conviction & 0.140 & 0.347 & 0.124 & 0.330 \\
\hline Female & 0.485 & 0.500 & 0.474 & 0.499 \\
\hline Birth year & 1981.388 & 6.617 & 1981.275 & 6.466 \\
\hline Only child & 0.236 & 0.424 & 0 & 0 \\
\hline \multicolumn{5}{|c|}{ Birth order in full families } \\
\hline 1st born & 0.615 & 0.487 & 0.421 & 0.494 \\
\hline 2nd born & 0.295 & 0.456 & 0.408 & 0.492 \\
\hline 3rd born & 0.073 & 0.260 & 0.133 & 0.34 \\
\hline$>=4$ th born & 0.018 & 0.132 & 0.038 & 0.191 \\
\hline Paternal age at birth & 29.499 & 5.682 & 29.569 & 5.475 \\
\hline Maternal age at birth & 26.563 & 5.081 & 26.583 & 4.849 \\
\hline Deceased at age 25 & 0.005 & 0.069 & 0.005 & 0.069 \\
\hline Age of decease & 20.696 & 2.765 & 20.584 & 2.755 \\
\hline Emigrated at age 25 & 0.030 & 0.172 & 0.029 & 0.169 \\
\hline Age of emigration & 21.620 & 2.189 & 21.641 & 2.145 \\
\hline $\mathrm{N}$ & 96774 & & 39679 & \\
\hline
\end{tabular}

of birth order since the full sample also comprises a quite large proportion of single child families $(23.6 \%)$.

In Table 2, we model the association between age at the time of a final paternal conviction and the children's conviction risk for any crime (a), violent crime (b), and property crime (c) in a set of population-averaged (bivariate in Model I and adjusted for measured 


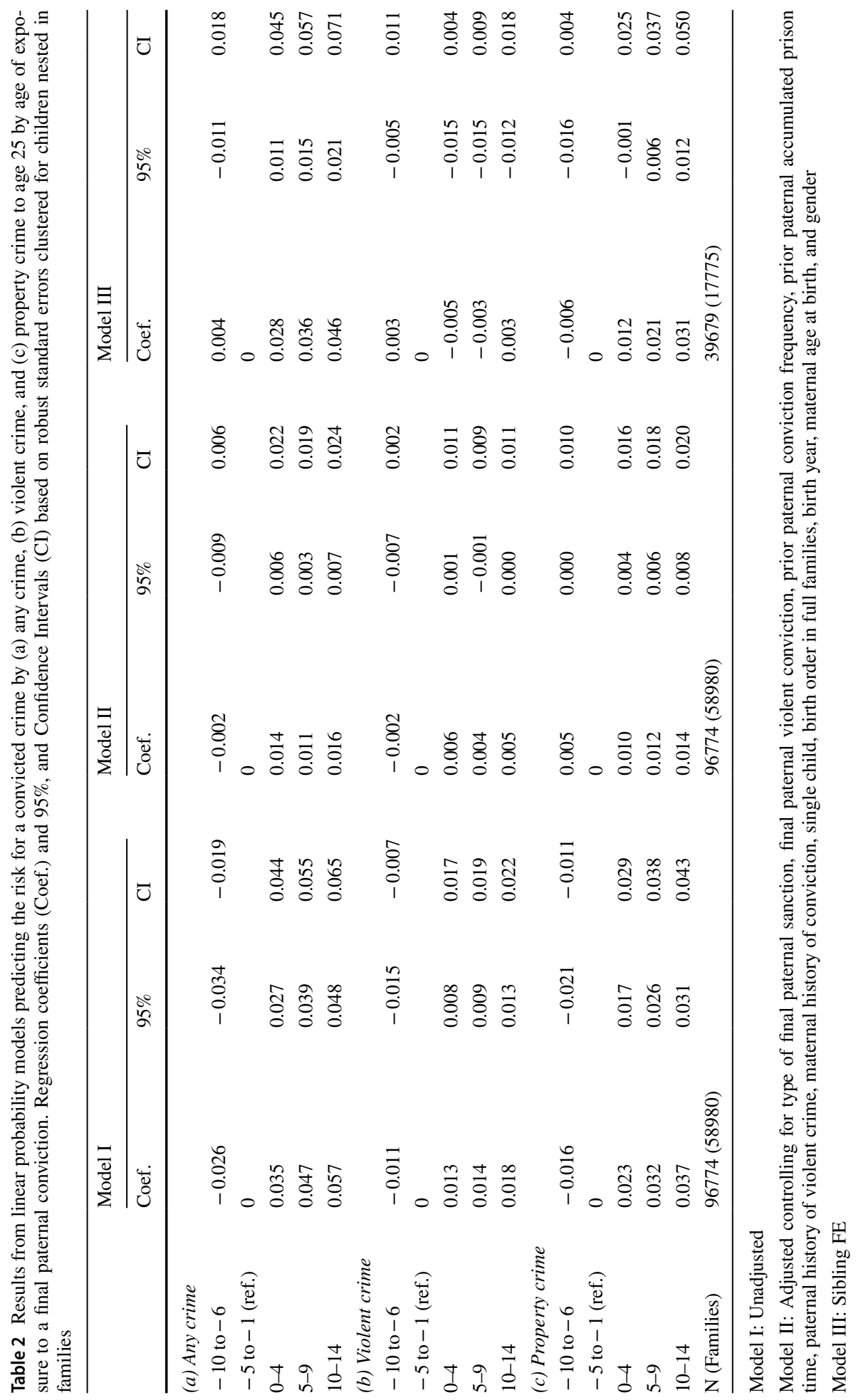


confounding in Model II) and sibling fixed-effects models (Model III). The coefficients reflect the change in the probability of a child conviction at ages 15-25 in a particular agecategory of exposure, compared to the reference category of children/siblings who were not born (but within five years to birth). These coefficients may also be interpreted in percentage points (abbreviated as pp and not to be confused with percentage change) by multiplying the values by 100 .

Table 2 shows a clear bivariate association between the exposure to a paternal conviction and child conviction risk regardless of type of crime. For children exposed to at paternal conviction at ages $0-4$, their own risk of a conviction increased by $3.5 \mathrm{pp}$ for any crime (1.3 pp and $2.3 \mathrm{pp}$ for violent crime and property crime respectively) compared to unexposed children within 5 years of birth. This is in line with previous studies using a similar bivariate comparison of children who were and were not born at the time of a paternal conviction (e.g. Bijleveld and Wijkman 2009). As shown by the age dummies, this association does not only regard exposed and unexposed children but across all age intervals, indicating that the later a father was convicted in the child's life, the higher was his or her risk for a criminal conviction. ${ }^{8}$

When controls for parental criminal history and childhood background characteristics are included (Model II), the association between exposure to a paternal conviction and offspring conviction risk becomes attenuated. The increased risk for children who were in ages 0-4 compared to unborn children within five years until birth are now only $1.4 \mathrm{pp}$ for any crime ( $0.6 \mathrm{pp}$ for violent crime and $1 \mathrm{pp}$ for property crime). Seeing from the confidence intervals, the difference between exposed and unexposed children remains statistically significant, but there is no longer any significant difference between children whose father was convicted prior to birth ( -10 to -6 vs. -5 to -1$)$ or between children who were at different ages at exposure during early childhood through the teens. The same pattern emerges when shifting the outcome to violent crime and property crime respectively, that is, the only remaining statistically significant difference is between exposed and unexposed children.

In the sibling fixed-effects models (Model III), there is also an attenuated difference between exposed and unexposed siblings compared to the bivariate model, suggesting that sibling-shared unobserved factors to some degree does confound the bivariate association. Full siblings exposed to a final paternal conviction at ages $0-4$ have a statistically significant increased risk for being convicted by $2.8 \mathrm{pp}$, compared to their unexposed younger siblings who were within five years of birth at the time of the final paternal conviction. Interestingly, the overrisk among exposed siblings concerns property crime, but not violent crime. It may also be noted that the age dummies for any crime and property crime show a slightly increased risk by increasing age of exposure. However, as can be seen from the confidence intervals, these differences do not reach conventional levels of statistical significance. This contradicts the notion of a sensitive age period during which a paternal conviction would be particularly impactful (e.g. Aaltonen and Mikkonen 2018; Besemer 2014).

Figures 1 and 2 show Kaplan-Meier cumulative probability functions for the bivariate association between exposure to a paternal conviction and offspring conviction risk

\footnotetext{
${ }^{8}$ It should be noted that all coefficients for the age-dummies for overall conviction risk are significantly different from each other (at the 0.05 level). This can be seen from comparing the $95 \%$ confidence interval of a given age dummy to the point estimate of any other given age dummy. However, although the same pattern is seen in violent and property crime, there are no significant age-differences in violent crime, and, for property crime, only the differences between age intervals $0-4$ and 5-9 are significant.
} 
(a) Any crime

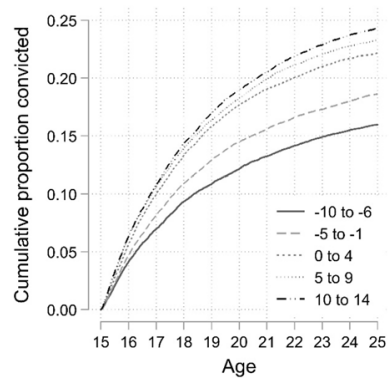

(b) Violent

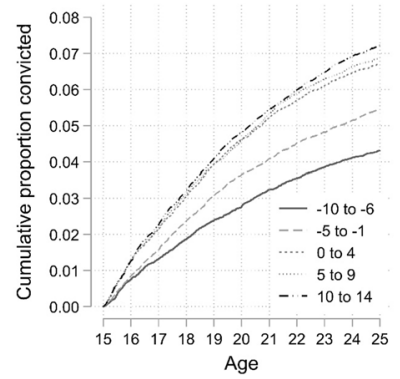

(c) Property

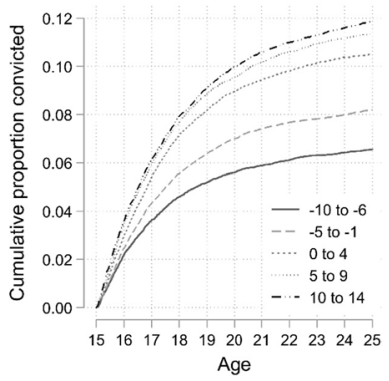

Fig. 1 Cumulative conviction probabilities for any crime (a), violent crime (b), and property crime (c) to age 25 in groups of children who were born at different points in time before and after a final paternal conviction. Note different scales

(a) Any crime

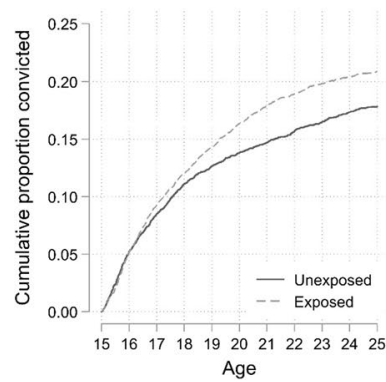

(b) Violent

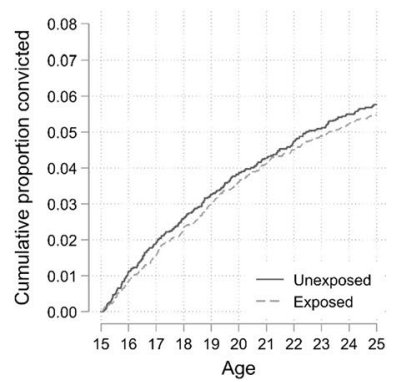

(c) Property

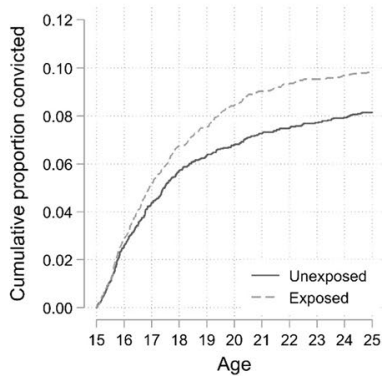

Fig. 2 Cumulative conviction probabilities for any crime (a), violent crime (b), and property crime (c) to age 25 in full siblings who were exposure-discordant to a final paternal conviction. Note different scales

in the full sample, and in exposure-discordant siblings respectively. These curves present nuanced age-graded cumulative risks for a conviction over the 10-year follow-up period. Thus, it also shows the proportion of individuals in the respective groups at risk who were eventually convicted at the end of the follow-up.

The probability of a conviction increases more markedly over the teenage years, followed by a less evident increase, a pattern replicating the typical age-crime association. This pattern is more distinct for property crime while the probability for a violent crime increases in a more linear fashion, confirming the general tendency for violent crime to be more evenly distributed across adolescence and emerging adulthood (DeLisi and Piquero 2011). Figure 1 essentially shows that the later the father experienced his final conviction, the higher is the probability of a subsequent child conviction. The differences are particularly marked when comparing groups of unexposed children to those who were exposed, whereas age-discordant children differ much less. This pattern is replicated regardless of crime type (but note that this is at the bivariate level of analysis).

Turning to the exposure-discordant full siblings in Fig. 2, the overrisk in exposed siblings remains for overall conviction risk and for property crime specifically, but not for violent crime. Broadly speaking, these curves mirror the substantial results from the models in Table 2. Interestingly though, these curves also indicate that the 10-year follow-up to 
(a) Males

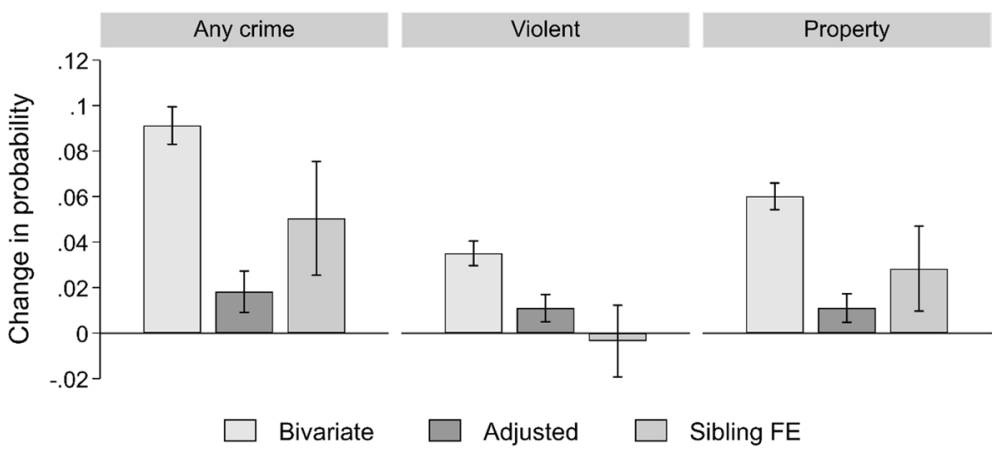

(b) Females

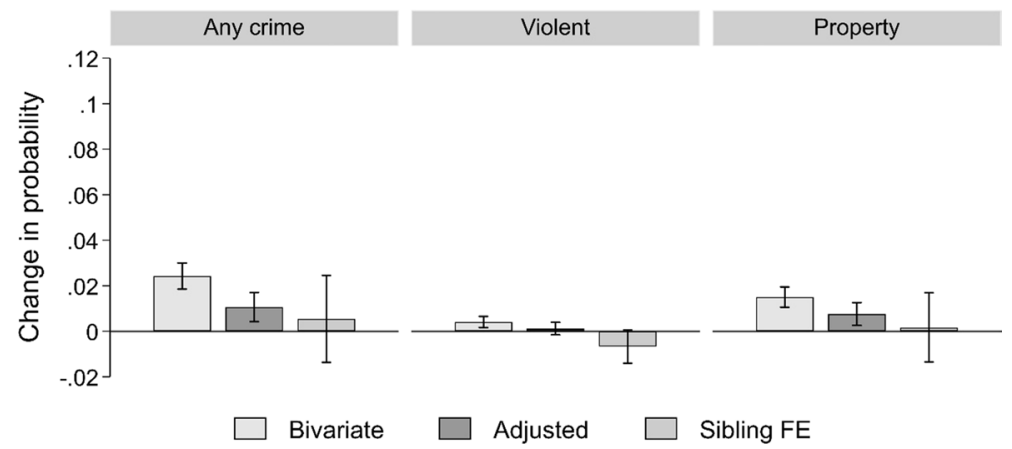

Fig. 3 Predicted change in conviction probability for any crime, violent crime, and property crime in exposure-discordant males/brothers (a) and females/sisters (b). Estimates from a set of population-averaged (bivariate and adjusted) and sibling fixed-effects models accompanied by $95 \%$ confidence intervals based on robust standard errors clustered for children nested in families

age 25 is informative as the differences between the compared groups increase somewhat with increasing age. This is particularly evident in the sibling analysis, where there is only a slight difference in the overall conviction risk, and for property crime, to age 18. After age 18, we observe divergent trends in the two groups. In contrast, the conviction risk for violent crime is parallel across the full age-span for exposure-discordant siblings, and there is no indication of any degree of divergence.

As a final set of analyses, we turn to the question of whether the results in the prior models are in any way moderated by gender. Figure 3 illustrates the predicted change in conviction probability by type of crime in exposure-discordant males/brothers (a) and females/sisters (b) respectively.

The overall bivariate associations are larger among males than among females, especially when it comes to violent crime. This is unsurprising since crime in general, and violent crime in particular, is much more prevalent in males than in females. As a result, it is reasonable that the associations are also larger among the males. What is more interesting is that the bivariate association among the females is in relative terms more attenuated than among the males when the two populations are restricted to a comparison of exposurediscordant sisters and brothers respectively. This suggests that the effects we see in the 
previous sibling models are almost entirely driven by brothers, and that it does not matter much for the conviction risk among sisters if they were, or were not, exposed to a paternal conviction. Finally, the previous models are replicated in males in that the exposure-discordant brothers differ in their overall conviction risk, and for property crime, but not for violent crime.

\section{Discussion}

The purpose of the present paper was to analyze the extent to which children who experience a final paternal conviction during their upbringing years are at an increased risk for being convicted themselves, compared to children whose fathers were convicted prior to their birth but not after. A second purpose was to explore whether or not we could find any evidence for a sensitive period during upbringing, where a paternal conviction may be particularly impactful. Drawing on recent quasi-experimental approaches to this question we utilized Swedish register-based data on a large sample of children and the potential to consider unmeasured sibling-shared confounding. In purely observational studies, such confounding may lead to an overestimation of the direct effect of a paternal conviction on the child's subsequent conviction risk.

Overall, our results suggest an effect of a final paternal conviction on the child's subsequent conviction risk; an effect we cannot fully explain by measured controls, including paternal conviction history, or by unmeasured sibling-shared confounding. At the same time, the findings clearly indicate a strong degree of selection on measured background factors and/or familial factors. As we included controls for measured confounding and when we ruled out sibling-shared confounding, the mere bivariate association between exposure to a paternal conviction and child conviction risk was attenuated. In this regard, two main findings should be highlighted: the bivariate association between a paternal conviction and violent crime in children diminished almost entirely in exposure-discordant siblings, and the effects in the main models were almost entirely driven by males. Moreover, in line with previous research, we found little evidence of a specific sensitive time period during childhood or early adolescence (e.g. Aaltonen and Mikkonen 2018; Besemer 2014).

Our findings resonate well with a long line of life-course research which shows that upbringing is an important phase of life that may have long-term effects (McLeod and Almazan 2003). The premise of our exposure-discordant sibling analysis is that the final paternal conviction occurred after the transition to parenthood but before the birth of the next child in line, and that the siblings share the same mother. This feature of our study design strengthens our inferences for an effect of a paternal conviction on the long-term conviction risk in children when it comes to generic offending and property crime, in that this effect cannot solely be a matter of sibling-shared characteristics. There may, of course, be a number of mechanisms by which the exposure to a parental conviction affects the offspring's criminal offending, and these mechanisms may also vary within families. The exposure to a paternal conviction may, for instance, be tied to an overall criminogenic environment, childrearing capabilities and/or to the stigma and/or loss associated with the criminal justice processing of a parent, all of which may co-occur with or cause dysfunctions in the family.

Our focus on a final paternal conviction may conceptually (on the level of the father) be connected to notions of desistance from crime. The desistance process tends to be 
associated with a number of changes in that person's life domains, including everyday routine activities such as employment and family life, and self-image (Giordano et al. 2002; Maruna 2001; Sampson and Laub 1993). As demonstrated by Massoglia and Uggen (2010), criminal offending and contact with the criminal justice system outside of the normative phase of delinquency, i.e. beyond adolescence, may hinder the timely transition to social adulthood. Although measuring desistance as a specific event, or rather the absence of an event, is neither conceptually nor empirically without issues (e.g. Maruna 2001), recidivism studies have demonstrated that the more time that passes since a person's latest conviction, the lower is the risk for a new conviction, often seen as an indicator of a process of desistance and change in that person's life (e.g. Blumstein and Nakamura 2009; Klingele 2019). Being born before or after the final paternal conviction occurred, may thus entail important consequences for the child's upbringing, with possibly long-term criminogenic effects.

However, while such an explanation was clearly supported by overall conviction risk, and for property crime specifically, it does not seem to hold for violent crime. As noted, a conviction is a relatively broad construct, including a wider set of, albeit criminalized, more normative youth behaviors such as shoplifting and minor use and possession of narcotics. As such, they may to a larger extent be driven by broader social dynamics outside of the family, for example association with peers (e.g. Warr 2002), whereas violence is more strongly tied to familial genetic and environmental risk factors (e.g. Caspi et al. 2002; Frisell et al. 2011). In this regard, it is also interesting that there was not much difference in overall conviction risk up to age 18 , but the overall difference appeared to be driven by the older age segment. Given the strong association between age of onset and subsequent career frequency and career length (DeLisi and Piquero 2011), this indicates that siblingshared factors may have stronger explanatory value for persistent offending and less so for occasional, less frequent, offending.

Finally, given our focus on paternal convictions, it was informative that the effects in the sibling models were almost entirely driven by the males whereas the exposure to a paternal conviction does not seem to have much influence on females. This suggests that sons are more impacted by the exposure to paternal criminal offending and criminal justice contact than are daughters, indicating gender-specific mechanisms at work. For example, children may adopt gender roles from their environment, and thus more closely identify with a parent who has the same characteristics as themselves (e.g. Auty et al. 2017). It is, however, also important to consider that boys may exhibit more externalizing problems, such as delinquency, as a response to parental criminal behavior and contact with the criminal justice system whereas girls display more internalizing problems, such as anxiety (Besemer et al. 2017). In other words, effects may also have been seen in exposure-discordant sisters had we been able to measure other outcomes.

\section{Limitations and Future Directions}

Using a conventional regression-based approach in combination with a sibling-comparison is a useful approach in moving research on the intergenerational transmission of crime forward. Despite its merits, however, this design is no panacea for causal inference. At least three limitations should be noted: (1) a loss of generalizability, (2) a loss of power, and (3) the inability to account for all family-varying confounding and mediating factors.

First, families in the full sample are non-informative for the sibling comparison if there is no variation between the siblings (i.e. all families where none of the children experienced 
paternal convictions, where both siblings experienced a paternal conviction within the same year, or when the family consisted of only one child). In this respect, it should also be mentioned that the families in the sibling model need to include at least two full siblings of the same sex, which further limits external validity. Our inferences are in this sense strengthened by the combination of a regression-based models and sibling comparisons (e.g. Connolly 2020), and in our study, the subsample of siblings were largely similar to the full sample on measured background factors. However, we cannot be certain that there are no systematic differences between different family compositions which would moderate the association between exposure to a paternal conviction and offspring conviction risk. Such an analysis would be able to further distinguish environmental from genetic sources of the parental and offspring crime association (e.g. Kendler et al. 2015).

Second, the breakdown into differently exposed siblings may cause a significant loss of statistical power in most applications. Our sample, however, consists of almost 40000 full same-sex siblings who were discordant in the age of a paternal conviction from ten years prior to birth through age 14. This clearly demonstrates an advantage of registerbased research. Still, an even larger sample would provide possibilities for further withinfamily analyses, for example with respect to the impact of paternal imprisonment and prison length. While exposure to a paternal conviction may generally be an indicator of the heightened social difficulties faced by a family during the sentence, evidence from quasiexperimental studies utilizing policy reforms suggests that paternal imprisonment, in particular, has deleterious effects on children in a number of social outcomes (Dobbie et al. 2018; Wildeman and Andersen 2017). Larger samples utilizing the linkage of family members could offer yet another strong quasi-experimental approach to further the knowledge on the potential mechanisms involved in the collateral consequences of imprisonment.

Finally, as with every research design that is not a randomized control trial, the analyses do not account for every possible variable that may confound the association of interest. It is possible that another unmeasured factor that varied between full siblings and cooccurred with a paternal conviction is the causal environmental risk factor. Relatedly, there are potentially important family-varying mediating variables which were not available in our data, including information on the living arrangements of the differently exposed siblings and information on changes in parental behavior and rearing practices. Research of the intergenerational continuity of crime could benefit from incorporating the wealth of knowledge produced in the desistance from crime literature as the environmental factors that facilitate desistance in the parental generation may also generate long-term effects in the subsequent generation.

\section{Conclusion}

In conclusion, the results of this study suggest that there is an effect of the exposure to a paternal conviction on male offspring conviction risk that cannot merely be explained by familial factors shared between full siblings. This is the case for generic offending and property crime specifically, but not for violent crime for which sibling-shared characteristics appears to have a stronger explanatory value. In other words, although crime tends to run in families, the current study suggests that there are also dynamics within the family that make some criminal outcomes more likely for boys who were exposed to a paternal conviction than for those who were not. 
Funding Open access funding provided by Stockholm University. This work was supported by the Swedish Research Council for Health, Working Life and Welfare (Grant No. 2016-07148) and The Swedish Research Council (Grant No. 2018-01452).

Open Access This article is licensed under a Creative Commons Attribution 4.0 International License, which permits use, sharing, adaptation, distribution and reproduction in any medium or format, as long as you give appropriate credit to the original author(s) and the source, provide a link to the Creative Commons licence, and indicate if changes were made. The images or other third party material in this article are included in the article's Creative Commons licence, unless indicated otherwise in a credit line to the material. If material is not included in the article's Creative Commons licence and your intended use is not permitted by statutory regulation or exceeds the permitted use, you will need to obtain permission directly from the copyright holder. To view a copy of this licence, visit http://creativecommons.org/licenses/by/4.0/.

\section{References}

Aaltonen M, \& Mikkonen J (2018) Using register-linkage data to study intergenerational continuity of criminal offending. In: Van De Weijer, SGA (ed.). Intergenerational continuity of criminal and antisocial behavior: an international overview of studies. Taylor \& Francis Ltd

Allison PD (2009) Fixed-effects regression models. Sage, London

Allison PD (2014) Event history and survival analysis. Sage, London

Almquist YB, Grotta A, Vågerö D, Stenberg SA, Modin B (2019) Cohort profile update: the Stockholm birth cohort study. Int J Epidemiol 49(2):367-367e

Angrist JD, Pischke J (2009) Mostly harmless econometrics: an empiricist's companion. Princeton University Press, Princeton

Auty KM, Farrington DP, Coid JW (2017) The intergenerational transmission of criminal offending: exploring gender-specific mechanisms. Br J Criminol 57(1):215-237

Besemer S (2014) The impact of timing and frequency of parental criminal behaviour and risk factors on offspring offending. Psychol, Crime Law 20(1):78-99

Besemer S, Ahmad SI, Hinshaw SP, Farrington DP (2017) A systematic review and meta-analysis of the intergenerational transmission of criminal behavior. Aggress Violent Beh 37:161-178

Bijleveld CJH, Wijkman M (2009) Intergenerational continuity in convictions: a five-generation study. Crim Behav Mental Health 19(2):142-155

Blumstein A, Nakamura K (2009) Redemption in the presence of widespread criminal background checks. Criminology 47(2):327-359

Breining S, Doyle J, Figlio DN, Karbownik K, Roth J (2020) Birth order and delinquency: evidence from Denmark and Florida. J Law Econ 38(1):95-142

Bushway SD, Tahamont S (2016) Modeling long-term criminal careers: what happened to the variability? J Res Crime Delinq 53(3):372-391

Caspi A, McClay J, Moffitt TE, Mill J, Martin J, Craig IW, Taylor A, Poulton R (2002) Role of genotype in the cycle of violence in maltreated children. Science 297(5582):851-854

Connolly EJ, Kavish N (2019) The causal relationship between childhood adversity and developmental trajectories of delinquency: a consideration of genetic and environmental confounds. $\mathrm{J}$ Youth Adolesc 48(2):199-211

Connolly EJ (2020) Further evaluating the relationship between adverse childhood experiences, antisocial behavior, and violent victimization: a sibling-comparison analysis. Youth Viol Juv Justice 18(1):3-23

Correia S (2017). Linear models with high-dimensional fixed effects: an efficient and feasible estimator. Working Paper. http://scorreia.com/research/hdfe.pdf

Coyne CA, Fontaine NM, Långström N, Lichtenstein P, D’Onofrio BM (2013) Teenage childbirth and young adult criminal convictions: a quasi-experimental study of criminal outcomes for teenage mothers. J Crim Just 41(5):318-323

D’Onofrio BM, Singh AL, Iliadou A, Lambe M, Hultman CM, Grann M, Lichtenstein P (2010) Familial confounding of the association between maternal smoking during pregnancy and offspring criminality: a population-based study in Sweden. Arch Gen Psychiatry 67(5):529-538

D’Onofrio BM, Lahey BB, Turkheimer E, Lichtenstein P (2013) Critical need for family-based, quasiexperimental designs in integrating genetic and social science research. Am $\mathrm{J}$ Public Health 103(S1):S46-S55 
DeLisi M, Piquero A (2011) New frontiers in criminal careers research, 2000-2011: a state-of-the-art review. J Crim Just 39(4):289-301

Dobbie W, Grönqvist H, Niknami S, Palme M, \& Priks M (2018) The intergenerational effects of parental incarceration. Working Paper. Princeton: Princeton University

Elder GH Jr, Johnson MK, Crosnoe R (2003) The emergence and development of life course theory. In: Mortimer JT, Shanahan MJ (eds) Handbook of the life course. Springer, Boston

Farrington DP (2002) Families and crime. In: Wilson JQ, Petersilia J (eds) Crime: public policies for crime control. Institute for Contemporary Studies Press, Oakland

Frisell T, Lichtenstein P, Långström N (2011) Violent crime runs in families: a total population study of 12.5 million individuals. Psychol Med 41(1):97-105

Giordano PC, Cernkovich SA, Rudolph J (2002) Gender, crime and desistance: toward a theory of cognitive transformation. Am J Sociol 107(4):990-1064

Gottfredson MR, Hirschi T (1990) A general theory of crime. Stanford University Press, Stanford, CA.

Hagan J, Dinovitzer R (1999) Collateral consequences of imprisonment, for children, communities, and prisoners. Crime Justice 26:121-162

Hjalmarsson R, Lindquist MJ (2012) Like godfather, like son exploring the intergenerational nature of crime. J Human Resour 47(2):550-582

Kendler KS, Ohlsson H, Morris NA, Sundquist J, Sundquist K (2015) A Swedish population-based study of the mechanisms of parent-offspring transmission of criminal behavior. Psychol Med 45(5):1093-1102

Klingele C (2019) Measuring change: from rates of recidivism to markers of desistance. J Crim Law Criminol 109(4):769-817

Kuja-Halkola R, Pawitan Y, D’Onofrio B, Långström N, Lichtenstein P (2012) Advancing paternal age and offspring violent offending: a sibling-comparison study. Dev Psychopathol 24(3):739-753

Kyvsgaard B (2002) The criminal career: The Danish longitudinal study. Cambridge University Press, New York

Lahey BB, D’Onofrio BM (2010) All in the family: comparing siblings to test causal hypotheses regarding environmental influences on behavior. Curr Dir Psychol Sci 19(5):319-323

Lyngstad T, Skardhamar T (2011) Nordic register data and their untapped potential for criminological knowledge. Crime Justice 40(1):613-645

Maruna S (2001) Making good: how ex-convicts reform and rebuild their lives. American Psychological Association, Washington

Massoglia M, Uggen C (2010) Settling down and aging out: toward an interactionist theory of desistance and the transition to adulthood. Am J Sociol 116(2):543-582

McLeod JD, Almazan E-P (2003) Connections between childhood and adulthood. In: Mortimer JT, Shanahan MJ (eds) Handbook of the life course. Springer, Boston

Mikkonen J, Savolainen J, Aaltonen M, Martikainen P (2020) Using age difference and sex similarity to detect evidence of sibling influence on criminal offending. Psychol Med. https://doi.org/10.1017/ S0033291720003724

Modin B (2002) Birth order and mortality: a life-long follow-up of 14200 boys and girls born in early 20th century Sweden. Soc Sci Med 54(7):1051-1064

Mood C (2010) Logistic regression: why we cannot do what we think we can do, and what we can do about it. Eur Sociol Rev 26(1):67-82

Rowe DC, Farrington DP (1997) The familial transmission of criminal convictions. Criminology 35(1):177-202

Sampson RJ, Laub JH (1993) Crime in the making: pathways and turning points through life. Harvard University Press, Harvard

Sariaslan A, Larsson H, D’Onofrio B, Långström N, Lichtenstein P (2014) Childhood family income, adolescent violent criminality and substance misuse: quasi-experimental total population study. Br J Psychiatry 205(4):286-290

Sariaslan A, Långström N, D’Onofrio B, Hallqvist J, Franck J, Lichtenstein P (2013) The impact of neighbourhood deprivation on adolescent violent criminality and substance misuse: a longitudinal, quasiexperimental study of the total Swedish population. Int J Epidemiol 42(4):1057-1066

Sjölander A, Frisell T, Kuja-Halkola R, Öberg S, Zetterqvist J (2016) Carryover effects in sibling comparison designs. Epidemiology 27(6):852-858

Stock JH, Watson MW (2008) Heteroskedasticity-robust standard errors for fixed effects panel data regression. Econom: J Econom Soc 76(1):155-74

van de Weijer S, Augustyn MB, Besemer S (2017) Intergenerational transmission of crime. In: Blokland A, van der Geest V (eds) The Routledge international handbook of life-course criminology. Routledge, London 
van de Rakt M, Ruiter S, De Graaf ND, Nieuwbeerta P (2010) When does the apple fall from the tree? Static versus dynamic theories predicting intergenerational transmission of convictions. J Quant Criminol 26(3):371-389

van de Rakt M, Murray J, Nieuwbeerta P (2012) The long-term effects of paternal imprisonment on criminal trajectories of children. J Res Crime Delinq 49(1):81-108

von Hofer H (2014) Crime and reactions to crime in 34 Swedish birth cohorts: from historical descriptions to forecasting the future. J Scand Stud Criminol Crime Prev 15(2):167-181

Warr M (2002) Companions in crime. Cambridge University Press, Cambridge

Wikström P-O, Oberwittler D, Treiber K, Hardie B (2012) Breaking rules: the social and situational dynamics of young people's urban crime. Oxford University Press, Oxford

Wildeman C, Andersen SH (2017) Paternal incarceration and children's risk of being charged by early adulthood: evidence from a Danish policy shock. Criminology 55(1):32-58

Publisher's Note Springer Nature remains neutral with regard to jurisdictional claims in published maps and institutional affiliations. 